\title{
Predictors of mortality in patients hospitalized for congestive heart failure with left ventricular ejection fraction $\geq 40 \%$
}

\author{
Saadia Sherazi, Scott McNitt, Naila Choudhary, Abrar H. Shah, \\ Mehmet K. Aktas, Adil Asgher, Karl Q. Schwarz, Wojciech Zareba
}

Department of Cardiology at University of Rochester Medical Center, Rochester, New York, United States

\begin{abstract}
Background: There are limited data regarding the predictors of mortality in patients with acute congestive heart failure (CHF) and left ventricular ejection fraction (LVEF) $\geq 40 \%$.

Methods: We evaluated clinical characteristics, mortality and prognostic factors in a sample of consecutive patients hospitalized for $\mathrm{CHF}$ with $\mathrm{LVEF} \geq 40 \%$. Multivariable Cox regression models were developed to predict mortality using baseline clinical characteristics and echocardiographic variables.

Results: The study population consisted of 191 patients, mean age $70 \pm 14.6$ years $(60 \%$ female) with average follow-up of $4.0 \pm 2.8$ years. Cumulative 5 -year mortality was $58 \%$ in the entire population and it was $59 \%$ in men and $57 \%$ in women $(p=0.411)$. In multivariable analyses, predictors of mortality were the following: blood urea nitrogen (BUN) $>25 \mathrm{mg} / \mathrm{dL}$ $(H R=1.77 ; p=0.002) ;$ absence of hypertension $(H R=1.58 ; p=0.032)$, left ventricular end diastolic dimension $(L V E D D) \leq 4.1 \mathrm{~cm}(H R=1.73 ; p=0.011)$ and $L V E F \leq 45 \%$ $(H R=1.69 ; p=0.027)$.

Conclusions: Patients hospitalized for heart failure with $L V E F \geq 40 \%$ have very high mortality. Absence of hypertension, elevated BUN and lower LVEF $\leq 45 \%$ indicate increased risk of short-and long-term mortality. Lower LVEDD is an independent predictor of mortality in heart failure patients with $L V E F \geq 40 \%$. (Cardiol J 2015; 22, 4: 382-390)
\end{abstract}

Key words: heart failure, left ventricular dimension, heart failure with preserved ejection fraction, hypertension

\section{Introduction}

Heart failure (HF) with preserved ejection fraction (HFpEF) is currently observed in $50 \%$ of all $\mathrm{HF}$ patients $[1,2]$. The incidence of $\mathrm{HFpEF}$ increases with age with higher prevalence among women and the most common underlying etiology is hypertensive heart disease [3-5]. This is in contrast to $\mathrm{HF}$ with reduced ejection fraction (HFrEF) which is more prevalent among men and more often due to ischemic heart disease. The prevalence of $\mathrm{HFpEF}$ is rising with a rate of $1 \%$ per year with no improvement in outcomes when compared with patients with HFrEF [1]. Despite significant advances in the treatment of congestive heart failure (CHF), short- and long-term mortality remains very high. Morbidity and mortality in HF$\mathrm{pEF}$ are also similar to values observed in patients with HFrEF [3]. The mortality burden of HFpEF is substantial, ranging from $10 \%$ to $30 \%$ annually and

Address for correspondence: Saadia Sherazi, MD, MS, Heart Research Follow-up Program, Cardiology Division,

University of Rochester Medical Center, 265 Crittenden Blvd., Rochester, NY 14642, tel: (585) 752-9508, fax: (585) 273-5283, e-mail: Saadia_sherazi@urmc.rochester.edu 
higher in epidemiological studies than in clinical trials [6]. The aim of this study was to evaluate the clinical characteristics, long-term mortality and to identify prognostic factors in patients hospitalized for acute $\mathrm{CHF}$ with left ventricular ejection fraction $(\mathrm{LVEF}) \geq 40 \%$.

\section{Methods}

\section{Study population}

Medical records of consecutive sample of patients hospitalized at the University of Rochester Medical Center for decompensated HF between January $1^{\text {st }} 2003$ to May $30^{\text {th }} 2003$ with LVEF $\geq 40 \%$ were evaluated. Patients were identified using International Classification of Diseases, Ninth revision (ICD9) codes specific for CHF (428.0-428.9) with documented LVEF in the hospital system. The index date was assigned at the first qualifying hospitalization. A detailed review of electronic medical records was carried out to confirm the presentation of decompensated CHF. Clinical demographics and baseline clinical data including history of hypertension, hyperlipidemia, coronary artery disease, prior history of percutaneous coronary intervention or coronary artery bypass graft, diabetes mellitus, and atrial fibrillation (AF) were collected by reviewing the electronic medical records. The electrocardiographic parameters recorded were rate, rhythm, QRS duration, QTc interval, and presence of bundle branch blocks. Use of following medications was recorded: diuretics, beta-blockers, angiotensin converting enzyme inhibitors, angiotensin receptor blocking agents, calcium channel blockers, and digoxin. The laboratory data collected were serum potassium, creatinine, blood urea nitrogen (BUN) and glomerular filtration rate (GFR), calculated using Modification of Diet in Renal Disease equation.

\section{Echocardiographic variables}

The echocardiographic variables were retrieved using the hospital electronic database for echocardiograms including: LVEF (\%), septal and lateral wall thickness, left atrial diameter, left ventricular end systolic diameter (LVESD), left ventricular end diastolic diameter (LVEDD), pulmonary artery systolic pressure, and left ventricular mass (LVM). All echocardiograms were performed using the American Society of Echocardiography guidelines.

\section{Endpoints}

The primary end point for this study was allcause mortality. Mortality data were obtained from
Social Security Death Index. The analyses were performed to predict 1-, 3-, and 5-year mortality. The study was approved by the Institutional Review Board.

\section{Statistical analyses}

Continuous variables were presented as means and standard deviation while categorical variables were presented as percentages. Comparison of baseline characteristics by mortality status (dead vs. alive) was performed with a t-test for continuous variables and $\chi^{2}$ test for categorical variables. The Cox proportional hazards model with best subset regression was used to determine which clinical and echocardiographic measurements were significantly related to mortality during follow-up of the study. For all echocardiographic variables, patients were divided into quartiles for analyses. For LVEF, a pre-specified cutoff point of $45 \%$ was used in the analyses. Where appropriate, Kaplan-Meier cumulative mortality curves were plotted to display trends in mortality over time. All statistical analyses were performed using SAS 9.2 soft ware. A p value $<0.05$ was considered statistically significant.

\section{Results}

\section{Patient characteristics and follow-up}

There were 200 patients identified from the medical records with CHF hospitalization and documented $\mathrm{LVEF} \geq 40 \%$. Nine patients were excluded based on findings of moderate to severe valvular disease. Study population was 191 with mean age $70 \pm 14.6$ years, $115(60 \%)$ female with a mean follow-up of $4.0 \pm 2.8$ years. The mean LVEF for the cohort was $54 \pm 7.4 \%$. One hundred and fortyfive $(76 \%)$ patients were white. Hypertension was present in 140 (74\%), coronary artery disease in 95 (50\%), diabetes in $83(43.7 \%)$ and AF in $59(31 \%)$ patients (Table 1 ).

\section{Mortality}

There were 129 deaths during the follow-up of $4.0 \pm 2.8$ years. Patients who died in the study follow-up, were older (72.2 \pm 13.5 vs. $66.0 \pm 15.8$, $\mathrm{p}=0.010)$, had higher BUN $[\mathrm{mg} / \mathrm{dL}](34.7 \pm 21.3$ vs. $28.3 \pm 21.9, \mathrm{p}=0.017)$ and a trend towards more AF (35\% vs. $23 \%, \mathrm{p}=0.09$ ). There were no differences in other clinical characteristics, laboratory data and use of medications between patients who died vs. alive (Table 1).

The cumulative 1 -year mortality was $25 \%$, 3 -year mortality was $41 \%$, and 5 -year mortality was $58 \%$ (Fig. 1). As shown in Figure 2, there was no 
Table 1. Baseline clinical characteristics of 191 patients hospitalized for heart failure with left ventricular ejection fraction $\geq 40 \%$.

\begin{tabular}{|c|c|c|c|c|}
\hline Variable & Overall $(n=191)$ & Alive $(n=62)$ & Dead $(n=129)$ & $\mathbf{P}$ \\
\hline Age [years] & $70.2 \pm 14.6$ & $66.0 \pm 15.8$ & $72.2 \pm 13.5$ & 0.010 \\
\hline Female & $115(60.2 \%)$ & $40(64.5 \%)$ & $75(58.1 \%)$ & 0.399 \\
\hline Caucasian & $145(75.9 \%)$ & $44(71.0 \%)$ & $101(78.3 \%)$ & 0.268 \\
\hline Systolic blood pressure [mm Hg] & $138 \pm 30.7$ & $138.9 \pm 30.7$ & $134.9 \pm 30.7$ & 0.719 \\
\hline Diastolic blood pressure [mm Hg] & $70.0 \pm 18.9$ & $73.2 \pm 17.9$ & $68.6 \pm 19.2$ & 0.160 \\
\hline Hypertension & $138(73.4 \%)$ & $47(77.0 \%)$ & $91(71.7 \%)$ & 0.433 \\
\hline Diabetes mellitus & $89(43.7 \%)$ & $26(42.6 \%)$ & $63(49.6 \%)$ & 0.369 \\
\hline Atrial fibrillation & $59(31.1 \%)$ & $14(23.0 \%)$ & $45(34.9 \%)$ & 0.097 \\
\hline Coronary artery disease & $94(49.5 \%)$ & $26(42.6 \%)$ & $68(52.7 \%)$ & 0.194 \\
\hline Hyperlipidemia & $62(33.3 \%)$ & $25(41.0 \%)$ & $37(29.6 \%)$ & 0.122 \\
\hline Creatinine [mg/dL] & $2.2 \pm 2.7$ & $2.4 \pm 3.3$ & $2.08 \pm 2.4$ & 0.652 \\
\hline Blood urea nitrogen & $32.7 \pm 21.6$ & $28.3 \pm 21.9$ & $34.7 \pm 21.3$ & 0.017 \\
\hline Glomerular filtration rate & $54.9 \pm 36.7$ & $56.2 \pm 36.7$ & $54.3 \pm 36.8$ & 0.601 \\
\hline QTc & $433.4 \pm 51.3$ & $431.6 \pm 67.1$ & $434 \pm 42.6$ & 0.793 \\
\hline QRS & $97.9 \pm 24.8$ & $94.7 \pm 20.5$ & $99.3 \pm 26.4$ & 0.569 \\
\hline ACE-I/ARB & $105(57.1 \%)$ & $38(64.4 \%)$ & $67(53.3 \%)$ & 0.167 \\
\hline Beta blockers & $125(67.9 \%)$ & $43(72.9 \%)$ & $82(65.6 \%)$ & 0.323 \\
\hline Calcium channel blockers & $52(28.1 \%)$ & $15(25.4 \%)$ & $37(29.4 \%)$ & 0.578 \\
\hline Diuretic & $166(89.7 \%)$ & $53(89.8 \%)$ & $113(89.7 \%)$ & 0.975 \\
\hline Digoxin & $32(17.3 \%)$ & $7(11.9 \%)$ & $25(19.8 \%)$ & 0.181 \\
\hline Statins & $83(45.6 \%)$ & $32(54.2 \%)$ & $51(41.5 \%)$ & 0.105 \\
\hline
\end{tabular}

Values are given as percentages or means \pm standard deviation; ACE-I — angiotensin converting enzyme inhibitor; ARB — angiotensin receptor blocker

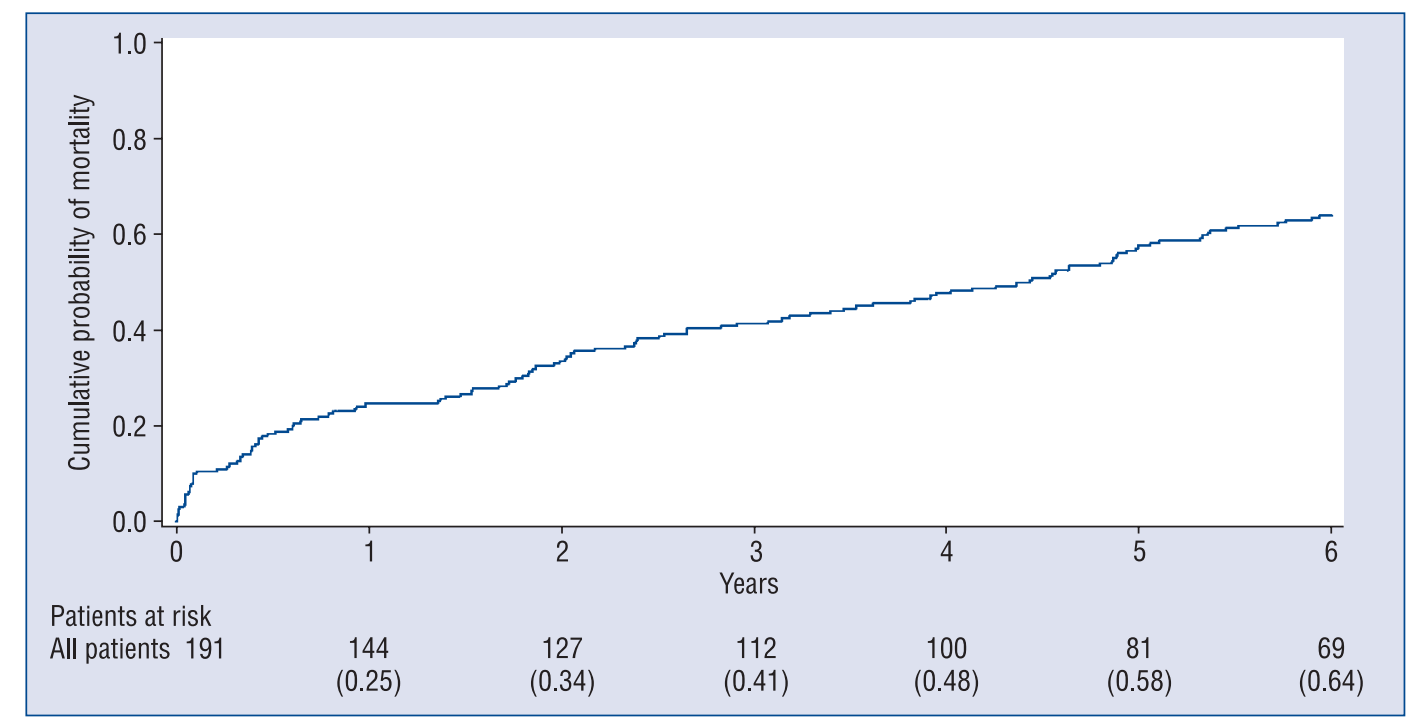

Figure 1. Cumulative 1-year mortality was $25 \%$, 3-year mortality was $41 \%$ and 5 -year mortality was $58 \%$.

difference in mortality between men and women $(p=0.411)$. Cumulative mortality among patients with history of hypertension vs. no history of hy- pertension and patients with $\mathrm{BUN}>25 \mathrm{mg} / \mathrm{dL}$ vs. BUN $\leq 25 \mathrm{mg} / \mathrm{dL}$ is shown in Figures $3 \mathrm{~A}$ and 3B, respetively. There was no difference in mortality 


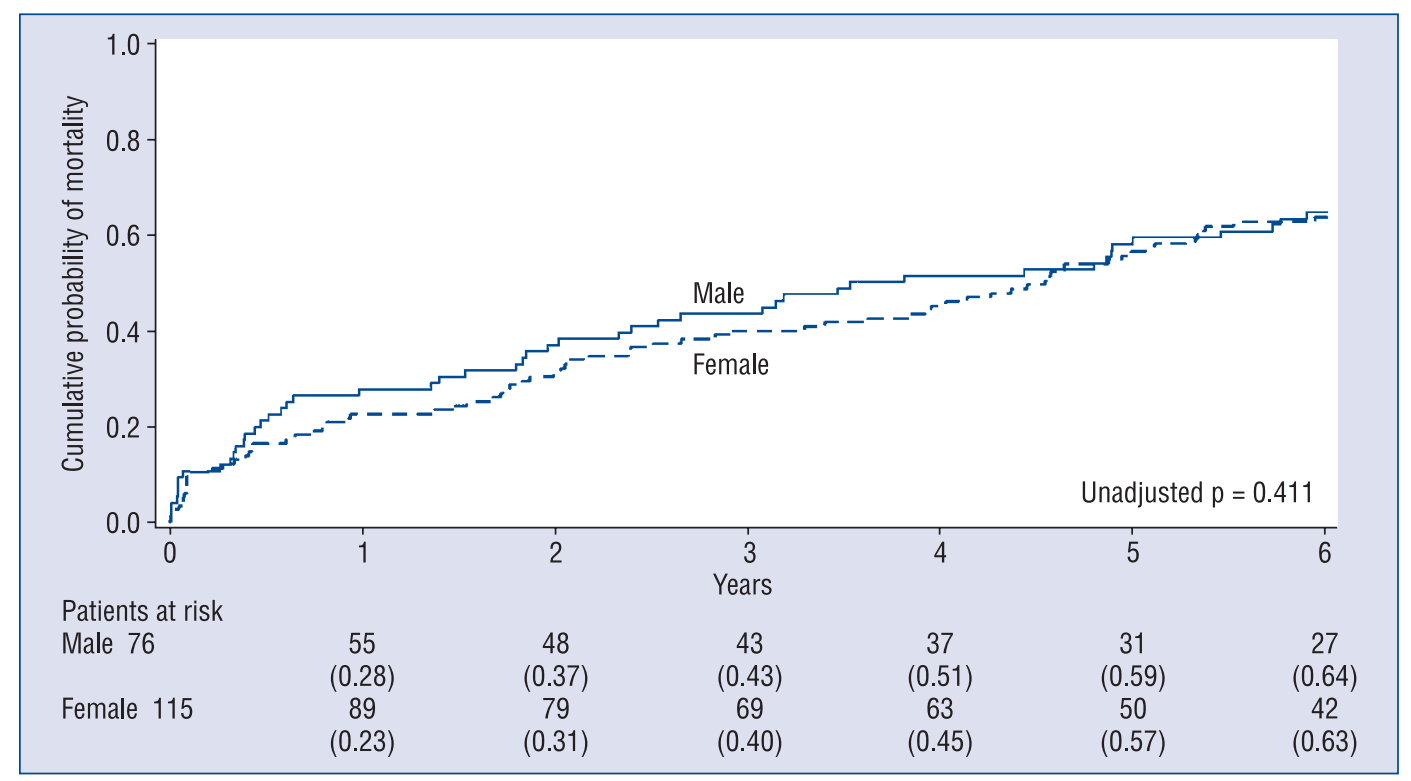

Figure 2. Cumulative mortality by gender in patients with left ventricular ejection fraction $\geq 40 \%$.

among patients with LVEF $\leq 45 \%$ and LVEF $>45 \%$ (Fig. $4 \mathrm{~A}, \mathrm{p}=0.402$ ). For all the echocardiographic variables presented in Table 2 , quartile distribution was examined and provided basis for grouping of values in dichotomous fashion comparing lower quartile (Q1) with upper quartiles (Q2-Q4). Among all of the echocardiographic variables, LVEDD lower quartile $\leq 4.1 \mathrm{~cm}$ compared with $>4.1 \mathrm{~cm}$ was the only significant variable that was associated with mortality. Mortalilty among quartiles of LVEDD and cumulative mortality among patients in $\mathrm{Q} 1$ of $\operatorname{LVEDD}(\leq 4.1 \mathrm{~cm})$ vs. Q2-Q4 $(>4.1 \mathrm{~cm})$ is shown in Figures $4 \mathrm{~B}$ and $4 \mathrm{C}$, respectively.

In multivariable Cox regression, predictors of mortality for the entire follow-up $(4.0 \pm 2.8$ years $)$ were: $\mathrm{BUN}>25 \mathrm{mg} / \mathrm{dL}(\mathrm{HR}=1.77, \mathrm{p}=0.002)$, absence of hypertension ( $\mathrm{HR}=1.61, \mathrm{p}=0.022)$, $\mathrm{LVEF} \leq 45 \%(\mathrm{HR}=1.69, \mathrm{p}=0.027)$, and LVEDD $\leq 4.1 \mathrm{~cm}(\mathrm{HR}=1.59, \mathrm{p}=0.026)$. At 1 year, the predictors of mortality were: BUN $>25 \mathrm{mg} / \mathrm{dL}$ $(\mathrm{HR}=2.65, \mathrm{p}=0.005)$, absence of hypertension (HR 2.30, $\mathrm{p}=0.01$ ) and LVEDD $\leq 4.1 \mathrm{~cm}$ $(\mathrm{HR}=1.70, \mathrm{p}=0.12)$ (Table 3$)$. Separate analysis evaluating the risk of mortality, defined as 3 -year and 5-year yielded similar results. There was no significant difference in LVM or LV wall thickness between patients with LVEDD $>4.1 \mathrm{vs.} \leq 4.1 \mathrm{~cm}$.

\section{Discussion}

Our study confirms that patients admitted with $\mathrm{HF}$ with a relatively preserved LVEF are at very high risk for short- and long-term mortality. Few studies have explored the prognostic factors that influence outcomes in this group of patients. Absence of hypertension, $\mathrm{BUN}>25 \mathrm{mg} / \mathrm{dL}, \mathrm{LVEF} \leq 45 \%$ and lower LVEDD were identified as important prognostic variables predicting mortality. In addition, the observed high mortality rate was independent of gender.

Hypertension is one of the major risk factors for development of diastolic dysfunction and subsequently HF. There is convincing data to support the statement that adequate control of hypertension decreases the incidence of new onset HF irrespective of the type of anti-hypertensive therapy administered [7]. Hypertension was reported in $74 \%$ of our study cohort, which is similar to the prevalence of hypertension in HFpEF reported in the literature. A recent study evaluated sex differences in baseline characteristics and outcomes in 4,128 patients enrolled in Irbesartan in Heart Failure with Preserved Ejection Fraction (I-PRESERVE) trial [8]. Hypertension was associated with a lower all-cause mortality $(\mathrm{HR}=$ $=0.845$ ) among women, however the p value did not reach statistical significance (0.138). Overall better prognosis seen in patients with hypertension could be explained by several mechanisms. Underlying etiologic mechanisms leading to diastolic HF other than hypertension, for example coronary artery disease and diabetes mellitus might be one of the reasons leading to higher mortality. As shown in a study by O'Connor et al. [9], the coronary artery disease index and diabetes mellitus were associated 


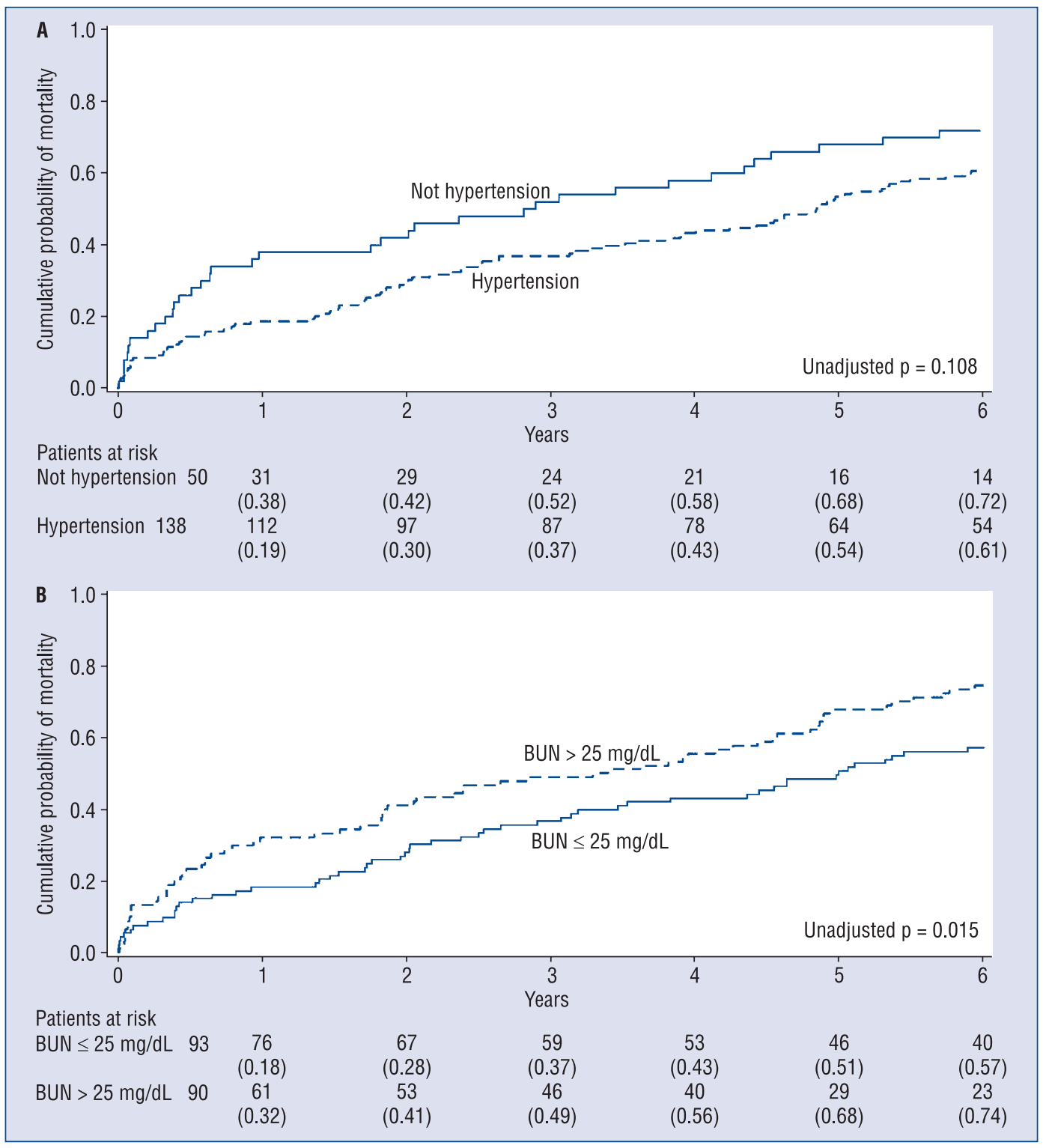

Figure 3. Cumulative mortality in patients with history of hypertension vs. no history of hypertension (A) and in patients with blood urea nitrogen $(B U N)>25 \mathrm{mg} / \mathrm{dL}$ vs. BUN $\leq 25 \mathrm{mg} / \mathrm{dL}$ (B).

with increased mortality in patients with $\mathrm{HF}$ and LVEF $>45 \%$. Furthermore, anti-hypertensive therapy for patients with hypertension may have resulted in the observed protective effect [7].

The association between abnormal renal function and increased risk of death and hospitalization in $\mathrm{HF}$ patients has previously been reported $[10,11]$. A post-hoc analysis of the Digitalis Investigation Group (DIG) trial demonstrated increasing mortality with decreasing quartile of creatinine clearance and 6 -min walking distance $<262 \mathrm{~m}$ [12]. Similarly, a post-hoc analysis of the Studies Of Left Ventricular Dysfunction (SOLVD) registry demonstrated worse combined outcome of hospitalization or death for the subset of patients with creatinine clearance $<60 \mathrm{~mL} / \mathrm{min}$ [13]. Impaired renal function represents advanced underlying $\mathrm{HF}$ and systemic disease whether it is hypertension, diabetes, or vascular disease resulting in high risk of mortality.

LVEF is a widely used clinical measure to assess left ventricular function and has been shown to predict mortality in HF patients with low ejection fraction (EF) [14]. The relationship between a wide range of LVEF and both fatal and non-fatal outcomes was assessed in 7,599 patients enrolled 


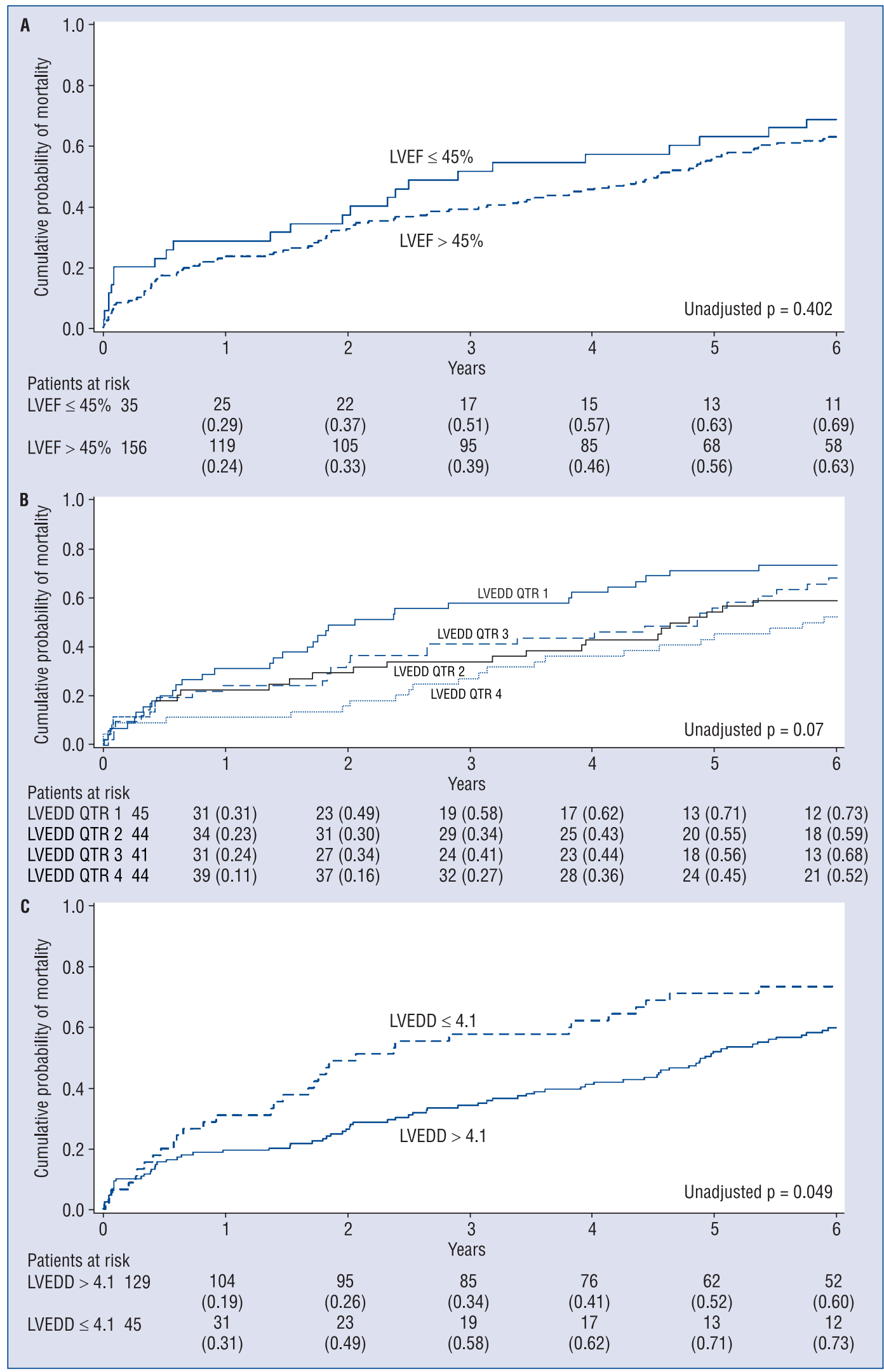

Figure 4. Cumulative mortality in patients with left ventricular ejection fraction (LVEF) $>45 \%$ vs. $\leq 36-45 \%$ (A), patients in quartiles of left ventricular end diastolic dimension (LVEDD) (B), and patients in quartile (QTR) 1 ( $\leq 4.1 \mathrm{~cm})$ vs. quartiles (QTR) 2-4 (> $4.1 \mathrm{~cm}$ ) of LVEDD (C). 
Table 2. Echocardiographic parameters by mortality status.

\begin{tabular}{lcccc}
\hline Echocardiographic parameters & Overall $(\mathbf{n}=\mathbf{1 9 1})$ & Alive $(\mathbf{n}=\mathbf{6 2})$ & Dead $(\mathbf{n}=\mathbf{1 2 9})$ & $\mathbf{P}$ \\
\hline LVEF [\%] & $54.6 \pm 7.4$ & $54.7 \pm 6.8$ & $54.6 \pm 7.7$ & 0.976 \\
LVEF $<45 \%$ & $18.3 \%$ & $16.1 \%$ & $19.4 \%$ & 0.587 \\
LVEDD [cm] & $4.6 \pm 0.7$ & $4.7 \pm 0.7$ & $4.6 \pm 0.7$ & 0.163 \\
LVEDD <4.1 [cm] & $25.9 \%$ & $21.1 \%$ & $28.2 \%$ & 0.312 \\
Left atrial diameter [cm] & $4.3 \pm 0.7$ & $4.3 \pm 0.7$ & $4.4 \pm 0.6$ & 0.674 \\
Left ventricular mass & $142.9 \pm 45.2$ & $148.8 \pm 49.2$ & $139.9 \pm 43$ & 0.376 \\
Posterior wall thickness [cm] & $1.2 \pm 0.2$ & $1.2 \pm 0.3$ & $1.2 \pm 0.2$ & 0.084 \\
Septal wall thickness [cm] & $1.3 \pm 0.3$ & $1.3 \pm 0.3$ & $1.3 \pm 0.3$ & 0.529 \\
PASP [mm Hg] & $45.7 \pm 13.6$ & $44.61 \pm 2.7$ & $46.3 \pm 14.1$ & 0.542 \\
\hline
\end{tabular}

LVEDD — left ventricular end diastolic dimension; LVEF — left ventricular ejection fraction; PASP — pulmonary artery systolic pressure

Table 3. Cox regression models for entire follow-up, 1-year, 3-year, and 5-year.

\begin{tabular}{|c|c|c|c|}
\hline Parameter & Hazard ratio & $95 \%$ hazard ratio confidence limits & $\mathbf{P}$ \\
\hline \multicolumn{4}{|l|}{ For entire follow-up } \\
\hline BUN > $25 \mathrm{mg} / \mathrm{dL}$ & 1.79 & $1.22-2.61$ & 0.002 \\
\hline Absence of hypertension & 1.58 & $1.03-2.42$ & 0.032 \\
\hline LVEDD < $4.1 \mathrm{~cm}$ & 1.73 & $1.13-2.65$ & 0.011 \\
\hline LVEF $\leq 45 \%$ & 1.69 & $1.06-2.72$ & 0.027 \\
\hline \multicolumn{4}{|l|}{ One-year mortality } \\
\hline $\mathrm{BUN}>25 \mathrm{mg} / \mathrm{dL}$ & 2.69 & $1.34-5.38$ & 0.005 \\
\hline Absence of hypertension & 2.23 & $1.14-4.37$ & 0.018 \\
\hline LVEDD $<4.1 \mathrm{~cm}$ & 1.82 & $0.91-3.64$ & 0.086 \\
\hline LVEF $\leq 45 \%$ & 1.65 & $0.74-3.69$ & 0.217 \\
\hline \multicolumn{4}{|l|}{ 3-year mortality } \\
\hline BUN > $25 \mathrm{mg} / \mathrm{dL}$ & 1.97 & $1.21-3.22$ & 0.006 \\
\hline Absence of hypertension & 1.60 & $0.95-2.69$ & 0.075 \\
\hline LVEDD $<4.1 \mathrm{~cm}$ & 2.30 & $1.37-3.87$ & 0.001 \\
\hline LVEF $\leq 45 \%$ & 2.05 & $1.14-3.67$ & 0.015 \\
\hline \multicolumn{4}{|l|}{ 5-year mortality } \\
\hline $\mathrm{BUN}>25 \mathrm{mg} / \mathrm{dL}$ & 1.95 & $1.29-2.95$ & 0.001 \\
\hline Absence of hypertension & 1.75 & $1.30-2.73$ & 0.012 \\
\hline LVEDD $<4.1 \mathrm{~cm}$ & 2.03 & $1.29-3.17$ & 0.001 \\
\hline LVEF $\leq 45 \%$ & 1.77 & $1.06-2.94$ & 0.027 \\
\hline
\end{tabular}

The following variables were entered in the model: atrial fibrillation, age $>75$ years, BUN $>25$, history of coronary artery bypass grafting, history of coronary artery disease, hypertension, hyperlipidemia, hematocrit, LVEDD, LVEDD (high risk quartile), LVEF > 50\%, LVEF < 45\%, LVEDD $<4.1 \mathrm{~cm}$; BUN — blood urea nitrogen; LVEDD - left ventricular end diastolic dimension; LVEF — left ventricular ejection fraction

in the CHARM (Candesartan in Heart Failure-Assessment of Reduction in Mortality) study population [15]. The mean LVEF was $38.8 \pm 14.9 \%$. The study concluded that LVEF predicts mortality with overall better survival in patients with increasing $\mathrm{EF}$ up to $45 \%$. For each $10 \%$ reduction in the EF below $45 \%$, the risk for total mortality increased by up to $39 \%$.
The role of left ventricle cavity size as a prognostic factor is well studied in patients with systolic HF. In a small sample of 50 patients with CHF with mean LVEF $32 \%$, LVEDD $(6.1 \mathrm{~cm})$ was not associated with increased mortality [16]. However, in the same study, the LVESD $(4.7 \mathrm{~cm})$ was significantly associated with higher mortality. In this study, patients with preserved LVEF were 
excluded. In our study, a smaller left ventricular cavity size $\leq 4.1 \mathrm{~cm}$ is associated with worse prognosis. Little is known regarding the prognostic significance of small cavity in $\mathrm{HFpEF}$ population. It is well described in the literature that patients with $\mathrm{HFpEF}$ have significant abnormalities in active relaxation and passive stiffness and generally have normal or even small left ventricular chamber volumes [17]. Due to increased passive stiffness of the left ventricle, significant changes in pressure may be seen even with little or no detectable change in ventricular volume [18]. Smaller cavity in HFpEF likely represents increased passive chamber stiffness; the ventricle is unable to accept venous return adequately without high diastolic pressures. Such high filling pressures result in worsening HF symptoms and increase mortality. Further studies are needed to evaluate the relationship between LVEDD and passive stiffness in patients with HFpEF.

We did not find age and $\mathrm{AF}$ as significant predictors of mortality independent of other covariates. This could be a result of small sample size. Other studies have shown age as one of the significant determinants of prognosis in patients with HFpEF [19]. The approximate 5-year mortality in patients with $\mathrm{HFpEF}$ rises with increasing age from $15 \%$ in patients $<50$ years to $33 \%$ in patients with age $50-70$ years and approaching $50 \%$ in patients $>70$ years old [19]. In our study, patients were relatively older $(70.2 \pm 14.6)$ and influence of age on mortality could not be demonstrated. AF is common among patients with $\mathrm{HFpEF}$ and it was reported in $31 \%$ patients in our study. CHARM sub-group analysis showed that patients with AF and preserved LVEF had higher risk for adverse cardiovascular outcome (34\% with cardiovascular death or CHF hospitalization) relative to those with preserved LVEF and sinus rhythm (21\%) [20]. After covariate adjustment, AF at baseline remained an independent predictor of all-cause mortality regardless of baseline LVEF. However, another report showed that AF was associated with an excessive mortality mainly related to the advanced age [21]. An explanation for variable results regarding prognostic significance of $\mathrm{AF}$ in $\mathrm{HFpEF}$ might be due to the differences in the study population. Alternatively, loss of atrial kick during AF may result in different hemodynamic effects among the patients with LVEF $>50 \%$ as compared with those with slightly reduced LVEF $40-50 \%$.

\section{Limitations of the study}

Our study has limitations, including the retrospective design and the small study cohort. We also lacked detailed systematic examination of the diastolic dysfunction in each patient and biomarkers such as troponin and B-type natriuretic peptide level. Neither the data on revascularization during the index hospitalization were analyzed. Further studies involving larger patient populations with detailed information on diastolic dysfunction are required to elucidate the validity of our clinical findings.

\section{Conclusions}

Mortality among patients hospitalized for HF with $L V E F \geq 40 \%$ remains very high. Prognosis of patients hospitalized for $\mathrm{HF}$ with $\mathrm{LVEF} \leq 45 \%$ is as poor as the prognosis of HF patients with LVEF $>45 \%$. Absence of hypertension and elevated BUN indicate increased risk of short- and long-term mortality. Patients hospitalized for HF with absence of hypertension need special care to improve their outcomes. LVEDD is found to be an independent predictor of mortality in HF patients with LVEF $\geq 40 \%$. A lower LVEDD may represent a "stiff" ventricle with compromised diastolic heart function.

\section{Conflict of interest: None declared}

\section{References}

1. Owan TE, Hodge DO, Herges RM, Jacobsen SJ, Roger VL, Redfield MM. Trends in prevalence and outcome of heart failure with preserved ejection fraction. N Engl J Med, 2006; 355: 251-259.

2. Bhatia RS, Tu JV, Lee DS et al. Outcome of heart failure with preserved ejection fraction in a population-based study. N Engl J Med, 2006; 355: 260-269.

3. Hogg K, Swedberg K, McMurray J. Heart failure with preserved left ventricular systolic function; epidemiology, clinical characteristics, and prognosis. J Am Coll Cardiol, 2004; 43: 317-327.

4. Yancy CW, Lopatin M, Stevenson LW, De Marco T, Fonarow GC, ADHERE Scientific Advisory Committee and Investigators. Clinical presentation, management, and in-hospital outcomes of patients admitted with acute decompensated heart failure with preserved systolic function: A report from the Acute Decompensated Heart Failure National Registry (ADHERE) Database. J Am Coll Cardiol, 2006; 47: 76-84.

5. Fonarow GC, Stough WG, Abraham WT et al. Characteristics, treatments, and outcomes of patients with preserved systolic function hospitalized for heart failure: A report from the OPTIMIZE-HF Registry. J Am Coll Cardiol, 2007; 50: 768-777.

6. Chan MM, Lam CS. How do patients with heart failure with preserved ejection fraction die? Eur J Heart Fail, 2013; 15: 604-613.

7. Solomon SD, Janardhanan R, Verma A et al. Effect of angiotensin receptor blockade and antihypertensive drugs on diastolic function in patients with hypertension and diastolic dysfunction: A randomised trial. Lancet, 2007; 369: 2079-2087.

8. Lam CS, Carson PE, Anand IS et al. Sex differences in clinical characteristics and outcomes in elderly patients with heart 
failure and preserved ejection fraction: The Irbesartan in Heart Failure with Preserved Ejection Fraction (I-PRESERVE) trial. Circ Heart Fail, 2012; 5: 571-578.

9. O'Connor CM, Gattis WA, Shaw L, Cuffe MS, Califf RM. Clinical characteristics and long-term outcomes of patients with heart failure and preserved systolic function. Am J Cardiol, 2000; 86: 863-867.

10. Go AS, Yang J, Ackerson LM et al. Hemoglobin level, chronic kidney disease, and the risks of death and hospitalization in adults with chronic heart failure: The Anemia in Chronic Heart Failure: Outcomes and Resource Utilization (ANCHOR) Study. Circulation, 2006; 113: 2713-2723.

11. Jones RC, Francis GS, Lauer MS. Predictors of mortality in patients with heart failure and preserved systolic function in the Digitalis Investigation Group trial. J Am Coll Cardiol, 2004; 44: 1025-1029.

12. Mahon NG, Blackstone EH, Francis GS, Starling RC,3rd, Young JB, Lauer MS. The prognostic value of estimated creatinine clearance alongside functional capacity in ambulatory patients with chronic congestive heart failure. J Am Coll Cardiol, 2002; 40: 1106-1113.

13. Dries DL, Exner DV, Domanski MJ, Greenberg B, Stevenson LW. The prognostic implications of renal insufficiency in asymptomatic and symptomatic patients with left ventricular systolic dysfunction. J Am Coll Cardiol, 2000; 35: 681-689.

14. St John Sutton M, Pfeffer MA, Moye L et al. Cardiovascular death and left ventricular remodeling two years after myocardial infarction: Baseline predictors and impact of long-term use of captopril: Information from the Survival and Ventricular Enlargement (SAVE) trial. Circulation, 1997; 96: 3294-3299.

15. Solomon SD, Anavekar N, Skali H et al. Influence of ejection fraction on cardiovascular outcomes in a broad spectrum of heart failure patients. Circulation, 2005; 112: 3738-3744.

16. Davies LC, Francis DP, Piepoli M, Scott AC, Ponikowski P, Coats AJ. Chronic heart failure in the elderly: Value of cardiopulmonary exercise testing in risk stratification. Heart, 2000; 83: 147-151.

17. Zile MR, Baicu CF, Gaasch WH. Diastolic heart failure: Abnormalities in active relaxation and passive stiffness of the left ventricle. N Engl J Med, 2004; 350: 1953-1959.

18. Kitzman DW, Higginbotham MB, Cobb FR, Sheikh KH, Sullivan MJ. Exercise intolerance in patients with heart failure and preserved left ventricular systolic function: Failure of the FrankStarling mechanism. J Am Coll Cardiol, 1991; 17: 1065-1072.

19. Zile MR, Brutsaert DL. New concepts in diastolic dysfunction and diastolic heart failure: Part I. Diagnosis, prognosis, and measurments of diastolic function. 2002; 105: 1387-1393.

20. Olsson LG, Swedberg K, Ducharme A et al. Atrial fibrillation and risk of clinical events in chronic heart failure with and without left ventricular systolic dysfunction: Results from the Candesartan in Heart failure-Assessment of Reduction in Mortality and morbidity (CHARM) program. J Am Coll Cardiol, 2006; 47: 1997-2004.

21. Rusinaru D, Leborgne L, Peltier M, Tribouilloy C. Effect of atrial fibrillation on long-term survival in patients hospitalised for heart failure with preserved ejection fraction. Eur J Heart Fail, 2008; 10: 566-572. 